\title{
Optimization of $\mathbf{N}$-benzyl-benzoxazol-2-ones as receptor antagonists of macrophage migration inhibitory factor (MIF)
}

\author{
Alissa A. Hare ${ }^{a}$, Lin Leng ${ }^{b}$, Sunilkumar Gandavadia ${ }^{a}$ Xin Du ${ }^{b}$, Zoe Cournia ${ }^{a}$, Richard \\ Bucala $^{b},{ }^{*}$, and William L. Jorgensen $a,{ }^{*}$ \\ a Department of Chemistry, Yale University, New Haven, CT 06520-8107, USA \\ b Department of Medicine, Yale University School of Medicine, New Haven, CT 06520-8066, USA
}

\section{Abstract}

The cytokine MIF is involved in inflammation and cell proliferation via pathways initiated by its binding to the transmembrane receptor CD74. MIF also exhibits keto-enol tautomerase activity, believed to be vestigial in mammals. Starting from a $1-\mu \mathrm{M}$ hit from virtual screening, substituted benzoxazol-2-ones have been discovered as antagonists with $\mathrm{IC}_{50}$ values as low as $7.5 \mathrm{nM}$ in a tautomerase assay and $80 \mathrm{nM}$ in a MIF-CD74 binding assay. Additional studies for one of the potent inhibitors demonstrated that it is not a covalent inhibitor of MIF and that it attenuates MIF-dependent ERK1/2 phosphorylation in human synovial fibroblasts.

MIF is a pro-inflammatory cytokine that is released by T-cells and macrophages. It plays a key role in a wide range of inflammatory diseases including rheumatoid arthritis, sepsis, and atherosclerosis. MIF is also involved in cell proliferation and differentiation, and anti-MIF antibodies suppress tumor growth and angiogenesis. The biology of MIF and potential biomedical significance of MIF-inhibition are striking. ${ }^{1-3}$ Studies have shown that MIF signal transduction is initiated by binding to a transmembrane protein, CD74. ${ }^{4,5} \mathrm{CD} 74$ expression is required for MIF-mediated ERK1/2 phosphorylation and cell proliferation, while inhibition of MIF-CD74 binding attenuates tumor growth and angiogenesis. ${ }^{4-6}$

Besides being a cytokine, MIF is also a keto-enol tautomerase. Though the catalytic activity of mammalian MIF is likely vestigial, ${ }^{7}$ there is evidence that the interaction of MIF with its receptor, $\mathrm{CD} 74$, occurs in the vicinity of the tautomerase active site. ${ }^{8}$ Crystal structures for MIF and MIF-tautomerase inhibitor complexes are available, ${ }^{2,9,10}$ though no structure for a MIF-CD74 complex has been reported. The 114-residue MIF monomer has a $\beta-\alpha-\beta$ motif and three monomers associate to form a symmetrical trimer. Each MIF trimer has three tautomerase active sites at the interfaces of the monomer subunits. The $N$-terminal proline resides in the tautomerase binding pocket and has an unusually low $\mathrm{p} K_{\mathrm{a}}$ of 5.6-6. ${ }^{11,12}$ This nucleophilic proline can effect the tautomerization of substrates and it also serves as a locus for covalent inhibition. For example, 4-iodo-6-phenylpyrimidine (4-IPP) was recently demonstrated through crystallography to form a covalent complex with MIF. ${ }^{13}$

*Corresponding author. richard.bucala@yale.edu, william.jorgensen@yale.edu.

Publisher's Disclaimer: This is a PDF file of an unedited manuscript that has been accepted for publication. As a service to our customers we are providing this early version of the manuscript. The manuscript will undergo copyediting, typesetting, and review of the resulting proof before it is published in its final citable form. Please note that during the production process errors may be discovered which could affect the content, and all legal disclaimers that apply to the journal pertain. 


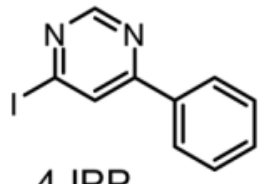
4-IPP

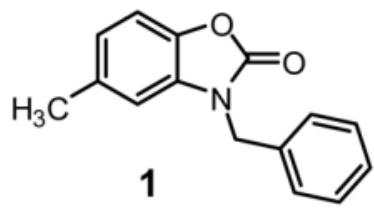

The emerging role of MIF in hyperproliferative and inflammatory diseases indicates that modulating the cytokine's activity can result in new therapies. ${ }^{1,2,14}$ To this end, we are seeking small-molecule inhibitors of MIF-CD74 complexation through structure-based design. In an initial report, virtual screening was highly successful in leading to identification of 11 structurally diverse inhibitors with activities in the $\mu \mathrm{M}$ regime. ${ }^{15} \mathrm{~N}$-benzyl-benzoxazol-2-one 1 was particularly compelling as it demonstrated inhibitory potencies of $0.5 \mu \mathrm{M}$ in the tautomerase assay and $1.5 \mu \mathrm{M}$ in the MIF-CD74 binding assay. Optimization of this hit has been pursued as summarized here.

A general route for the synthesis of analogues of $\mathbf{1}$ is shown in Scheme 1. 2-Aminophenols were acylated with 4-nitrophenyl chloroformate to yield benzoxazol-2-ones $\mathbf{2}$, which were alkylated with substituted benzyl bromides to form the desired analogues $\mathbf{3}$. Alcohols were typically obtained from the corresponding methyl ethers as in the conversion of $\mathbf{4}$ to $\mathbf{5}$. Most reactions proceeded in $70-80 \%$ yield. The identity of all assayed compounds was confirmed by ${ }^{1} \mathrm{H}$ (Bruker DRX-500) and ${ }^{13} \mathrm{C}$ NMR and HRMS; purity was normally $>95 \%$ as determined by reverse-phase HPLC. The choices of analogues that were synthesized and assayed were guided by computational modeling of the corresponding complexes with MIF, as described more below.

The tautomerase and MIF-CD74 assays were performed as previously presented. ${ }^{15}$ The former used 4-hydroxyphenylpyruvate (4-HPP) as the substrate, while the latter features biotinylated MIF and immobilized CD74 ectodomain (CD74 ${ }^{73-232}$ ) with streptavidin conjugated alkaline phosphatase processing $p$-nitrophenylphosphate as the reporter. Compounds were tested at concentrations over 500 to 5000 -fold ranges. Human MIF, prepared recombinantly, was used throughout. ${ }^{16}$

The assay results are summarized in Table 1. In considering the data, a complicating issue is that MIF is a trimer with three active sites. It is likely that this contributes to the common behavior in both assays where the dose-response curves show initial linearity, but may not reach 50\% inhibition. In these cases, the maximum percent inhibition is reported since the $\mathrm{IC}_{50}$ is not defined. For example, the results for $\mathbf{5}$ in the two assays are shown in Figure 1. Also, a simple correlation between the results for the two assays is not expected since one measures the inhibition of MIF's tautomerase activity and the other the inhibition of the proteinprotein recognition between MIF and CD74. For example, a small, but potent tautomerase inhibitor might have little structural effect on the surface of MIF and, therefore, little effect on MIF-CD74 binding. The equilibria may also be such that a weak tautomerase inhibitor has negligible influence on CD74 binding uncomplexed MIF. The activity data will be considered after discussion of computed results for the MIF-3 complexes.

Docking calculations for all complexes were carried out using Glide $5.5^{17}$ in the extra precision (XP) mode $^{18}$ and the $1 \mathrm{CA} 7$ crystal structure for MIF. ${ }^{9}$ Such computations yield predicted structures for the protein-ligand complexes and a score that is proportional to the expected free energy of binding. The XP scoring is the most accurate with Glide; it considers the details of the protein-ligand binding, internal energy of the ligand, desolvation, and hydrophobic interactions. ${ }^{18}$ Additional model building and energy minimizations were performed with $B O M B$ and $M C P R O$ using the OPLS/CM1A force field. ${ }^{19-21}$ In the previous study, it was demonstrated that Glide 4.0 XP scores correlated well with experimental $\log K_{\mathrm{i}}$ or $\log \mathrm{IC}_{50}$ 
values for complexes of 10 known MIF tautomerase inhibitors. ${ }^{15}$ The calculations were repeated here with Glide 5.5 with similar outcome; the correlation coefficient $r^{2}$ improved a little from 0.75 to 0.78 , while the range of XP scores was compressed from 7 units to 1.5 units. The most favorable XP score, -9.4 , for the known inhibitors is for a coumarin derivative with a reported $K_{\mathrm{i}}$ of $38 \mathrm{nM},{ }^{2}$ and inhibitors with $K_{\mathrm{i}}$ values near $1 \mu \mathrm{M}$ gave XP scores near -9.0. These values can be compared to the results obtained for 1-38 in Table 1. Clearly, some of the compounds are expected to be MIF tautomerase inhibitors, though the correlation between the $\mathrm{XP}$ scores and tautomerase $\log \mathrm{IC}_{50}$ values is weak with an $\mathrm{r}^{2}$ of ca. 0.3 .

The preferred binding mode for 1-38 with MIF from XP Glide features the benzoxazol-2-one fragment inserted into the active-site cavity and the benzyl substructure facing outwards near the protein's surface. This was noted previously for $\mathbf{1 ,}{ }^{15}$ and the corresponding "in" complex is illustrated for $\mathbf{5}$ in Figure 2. The structure allows favorable hydrogen bonding with the NH of Ile64, electrostatic interactions with the side chain of Lys32, and aryl-aryl interactions with Tyr36, Tyr95, and Phe113. Furthermore, it is consistent with overlaying the chromen-2-one fragment from the inhibitor in the $1 \mathrm{GCZ}$ crystal structure ${ }^{2}$ and the benzoxazol-2-one ring system (Scheme 2). The calculations with Glide also find a reversed "out" MIF binding mode with the benzyl ring inserted into the cavity towards Asn97. However, the XP scores for the reversed mode are generally several units less favorable; such structures generated with $B O M B$ and $M C P R O$ were also not competitive. Nevertheless, in the absence of experimental structural data, the binding mode or modes of analogues of $\mathbf{3}$ are uncertain. Indeed, an alternative conformation has been found recently for Tyr36 that leads to binding for some inhibitors on the protein's surface between Tyr36 and Phe113. ${ }^{10}$

Returning to Table 1, potent inhibitors were identified in both assays. Notably, $\mathbf{5}$ and $\mathbf{1 9}$ give $\mathrm{IC}_{50}$ values in the 5-10 $\mathrm{nM}$ range in the tautomerase assay, while $\mathbf{6}, \mathbf{2 0}$, and $\mathbf{2 5}$ fall in the 80$120 \mathrm{nM}$ range in the MIF-CD74 binding assay. For the tautomerase inhibitors, it is best to have a 3-OH group in the benzyl ring and a 5- or 6- $\mathrm{CH}_{3}$ in the heterocycle. Larger groups on the heterocycle, as in $\mathbf{2 3}, \mathbf{2 5}$, and $\mathbf{3 3}$, lead to diminished activity. In the "in" geometry, there appear to be steric clashes for groups larger than methyl at the 5- and 6-positions, and energy minimizations suggest that the 3-OH may benefit from hydrogen bonding to the $\mathrm{C}=\mathrm{O}$ of $\mathrm{Tyr} 36$ (Figure 2) or via a water bridge to the $\mathrm{C}=\mathrm{O}$ of Phe113. In the "out" mode, the 3-OH might form a hydrogen bond with Asn97; however, the 5- and 6-substituents are then largely solvent exposed, and the size restriction does not make sense. The results for the MIF-CD74 binding are harder to interpret owing to the even greater structural uncertainties. Many compounds do show significant inhibitory power, though many did not reach the $50 \%$ level. The most active compounds have an $\mathrm{OH}$ or $\mathrm{OCH}_{3}$ group at the 2- and/or 3-position in the benzyl ring and a $\mathrm{CH}_{3}$ or $\mathrm{OCH}_{3}$ group at the 5-position in the heterocycle.

Some additional studies have been carried out to further characterize the MIF inhibition. First, Michaelis-Menten analyses previously confirmed that $\mathbf{1}$ is a competitive inhibitor of MIF's tautomerase activity. ${ }^{15}$ As many MIF inhibitors have been reported to function by covalent attachment to Pro1 or Cys residues, ${ }^{13,22}$ mass spectrometry (Bruker 9.4T APEX-Qe FTICR) was used to examine this possibility for the potent 5 and for 4-IPP as a control. $10 \mu \mathrm{l}$ of rhMIF $(30 \mu \mathrm{M})$ were added to $10 \mu \mathrm{l}$ of $30 \mu \mathrm{M}$ 4-IPP or 5 and $1 \mu \mathrm{l}$ of $1 \%$ FA buffer. In the case of 4-IPP, these conditions result in $90 \%$ tautomerase inhibition and 50\% inhibition of MIF receptor binding, ${ }^{13}$ while for $\mathbf{5}, 50 \%$ inhibition is observed for both MIF activities. The samples were incubated for $1 \mathrm{hr}$ at room temperature in the dark and desalted using $\mathrm{ZipTipC}_{18}$, eluting into $10 \mu \mathrm{l} 60 \%$ acetonitrile/0.1\% FA.

The expected mass spectrometric behavior was observed for 4-IPP with appearance of the covalent adduct at the mass of MIF + ca. $155 \mathrm{Da}$ (Figure 3), while for $\mathbf{5}$ no additional peaks emerged, though the scan was analyzed beyond the expected combined mass of MIF $+\mathbf{5}$ (255 
Da). 4-IPP is a potent MIF inhibitor by virtue of its covalent interaction with Pro1. ${ }^{13}$ However, not all of the protein was modified, and covalent reaction may not fully account for the MIFinhibitory activity of 4-IPP. In fact, the covalent inhibitor NAPQI, which also decreases MIF tautomerase and receptor binding activities, ${ }^{8}$ was recently reported to additionally bind to MIF in a non-covalent manner. ${ }^{23}$

Finally, inhibition of MIF signal transduction by $\mathbf{5}$ in human target cells was explored. The extracellular-signal-regulated kinase (ERK) pathway is of particular interest as aberrations in it are associated with hyperproliferative diseases as well as autoimmune disorders including rheumatoid arthritis (RA). Thus, inhibition of ERK phosphorylation has promising therapeutic potential. ${ }^{14,24}$ Specifically, synovial fibroblasts from a patient with RA were incubated with MIF (1.3 nM trimer) together with vehicle control (DMSO) or $5(300 \mathrm{nM})$. The cells were lysed after $30 \mathrm{~min}$ and the intracellular content of phospho-ERK1/2 and total ERK1/2 were detected by specific antibodies and western blotting (Figure 4). Addition of MIF enhances ERK1/2 phosphorylation, ${ }^{4}$ while co-administration of $\mathbf{5}$ strongly inhibits the process. The observations are consistent with the observed inhibitory effect of $\mathbf{5}$ on MIF-CD74 binding (Figure 1).

In summary, optimization of MIF inhibitor $\mathbf{1}$, which arose from virtual screening, ${ }^{15}$ has been pursued. Multiple highly potent inhibitors of MIF's keto-enol tautomerase activity and of the binding of MIF to its functional receptor, CD74, have been discovered. Computational work has suggested structures for the MIF-inhibitor complexes, though improved understanding of the activity data awaits experimental structural results. Additional investigations for the potent inhibitor $\mathbf{5}$ were carried out that demonstrated that it is not a covalent inhibitor of MIF and that it is active in suppressing MIF-dependent ERK phosphorylation in human synovial fibroblasts.

\section{Acknowledgments}

Gratitude is expressed to T. Lam and E. Voss of the Keck Biotechnology Facility and the National Institutes of Health (AI043210, AR049610, AR050498, GM032136) for support.

\section{References}

1. Bucala R. Nature 2000;408:146. [PubMed: 11089953]

2. Orita M, Yamamoto S, Katayama N, Fujita S. Curr Pharm Des 2002;8:1297. [PubMed: 12052220]

3. Morand EF, Leech M, Bernhagen J. Nat Rev Drug Discov 2006;5:399. [PubMed: 16628200]

4. Leng L, Metz CN, Fang Y, Xu J, Donnelly S, Baugh J, Delohery T, Chen Y, Mitchell RA, Bucala R. J Exp Med 2003;197:1467. [PubMed: 12782713]

5. Shi X, Leng L, Wang T, Wang W, Du X, Li J, McDonald C, Chen Z, Murphy JW, Lolis E, Noble P, Knudson W, Bucala R. Immunity 2006;25:595. [PubMed: 17045821]

6. Meyer-Siegler KL, Iczkowski KA, Leng L, Bucala R, Vera PL. J Immunol 2006;177:8730. [PubMed: 17142775]

7. Fingerle-Rowson G, Kaleswarapu DR, Schlander C, Kabgani N, Brocks T, Reinart N, Busch R, Schütz A, Lue H, Du X, Liu A, Xiong H, Chen Y, Nemajerova A, Hallek M, Bernhagen J, Leng L, Bucala R. Mol Cell Biol 2009;29:1922. [PubMed: 19188446]

8. Senter PD, Al-Abed Y, Metz CN, Benigni F, Mitchell RA, Chesney J, Han J, Gartner CG, Nelson SD, Todaro GJ, Bucala R. Proc Natl Acad Sci USA 2002;99:144. [PubMed: 11773615]

9. Lubetsky JB, Swope M, Dealwis C, Blake P, Lolis E. Biochemistry 1999;38:7346. [PubMed: 10353846]

10. McLean LR, Zhang Y, Li H, Choi YM, Han Z, Vaz RJ, Li Y. Bioorg Med Chem Lett 2010;20:1821. [PubMed: 20185308]

11. Stamps SL, Fitzgerald MC, Whitman CP. Biochemistry 1998;37:10195. [PubMed: 9665726] 
12. Soares TA, Goodsell DS, Ferreira R, Olson AJ, Briggs JM. J Mol Recognit 2000;13:146. [PubMed: 10867710]

13. Winner M, Meier J, Zierow S, Rendon BE, Crichlow GV, Riggs R, Bucala R, Leng L, Smith N, Lolis E, Trent JO, Mitchell RA. Cancer Res 2008;68:7253. [PubMed: 18794110]

14. Bucala R, Lolis E. Migration inhibitory factor: A critical component of autoimmune inflammatory diseases. Drug News Perspect 2005;18:417. [PubMed: 16362080]

15. Cournia Z, Leng L, Gandavadi S, Du X, Bucala R, Jorgensen WL. J Med Chem 2009;52:416. [PubMed: 19090668]

16. Bernhagen J, Mitchell RA, Calandra T, Voelter W, Cerami A, Bucala R. Biochemistry 1994;33:14144. [PubMed: 7947826]

17. Glide, version 5.5. Schrödinger, LLC; New York, N.Y: 2009.

18. Friesner RA, Murphy RB, Repasky MP, Frye LL, Greenwood JR, Halgren TA, Sanschagrin PC, Mainz DT. J Med Chem 2006;49:6177. [PubMed: 17034125]

19. Jorgensen WL, Tirado-Rives J. J Comput Chem 2005;26:1689. [PubMed: 16200637]

20. Jorgensen WL, Tirado-Rives J. Proc Natl Acad Sci USA 2005;102:6665. [PubMed: 15870211]

21. Jorgensen WL. Acc Chem Res 2009;42:724-733. [PubMed: 19317443]

22. Ouertatani-Sakouhi H, El-Turk F, Fauvet B, Cho M-K, Karpinar DP, Le Roy D, Dewor M, Roger T, Bernhagen J, Calandra T, Zweckstetter M, Lashuel HA. J Biol Chem 2010;M110:113951. In press.

23. Crichlow GV, Lubetsky JB, Leng L, Bucala R, Lolis EJ. Biochemistry 2009;48:132. [PubMed: 19090677]

24. Ohori M. Drug News Perspec 2008;21:245. 

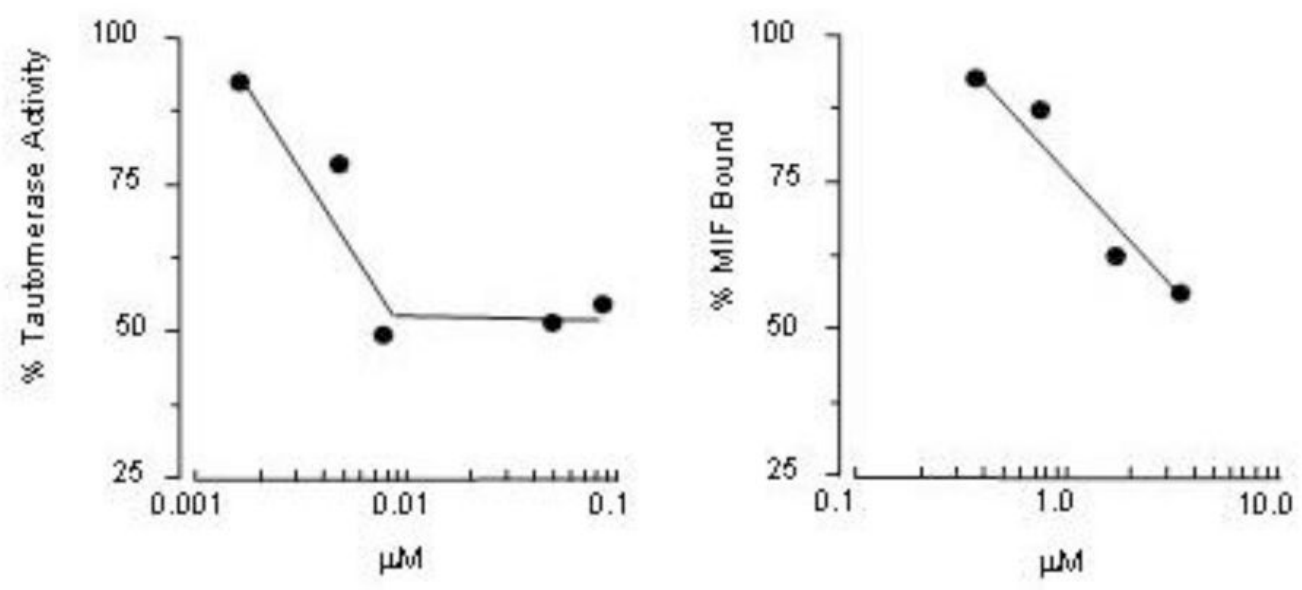

Figure 1.

Results of assays performed in triplicate for $\mathbf{5}$. 


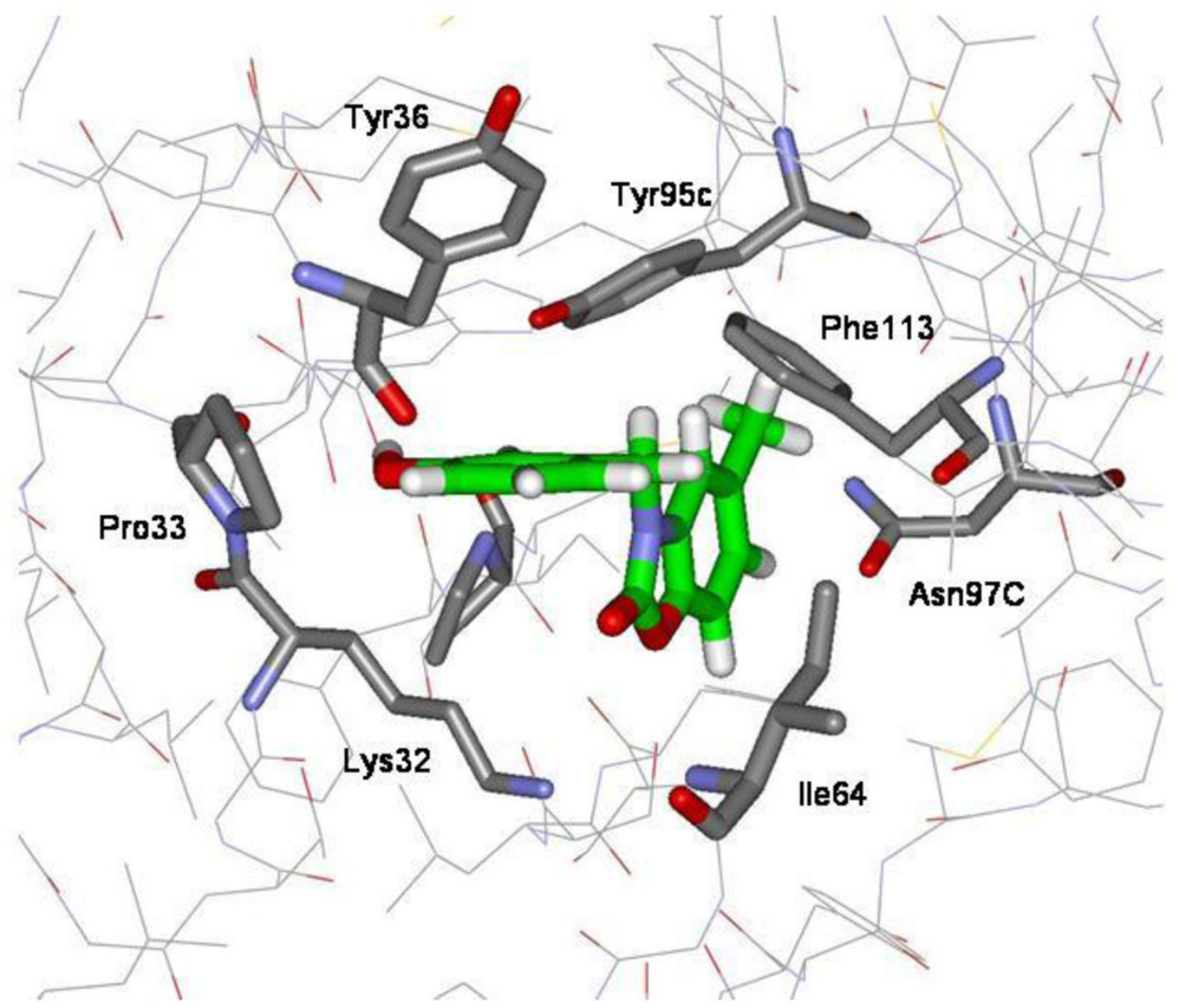

Figure 2.

Computed structure for 5 bound to MIF after energy minimization with MCPRO. Carbon atoms of 5 are in green. 

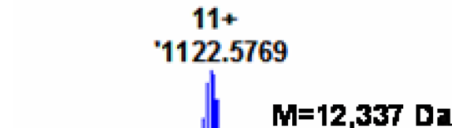

$M=12,337$ Da
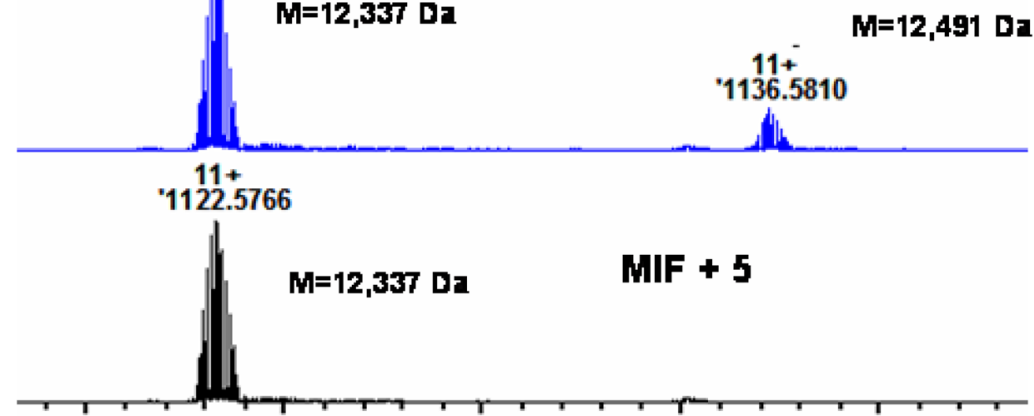

1120
$M=12,337$ Da

1125
MIF + 4-IPP

MIF + 5 $1140 \mathrm{~m} / \mathrm{z}$

Figure 3.

Mass spectrometry results showing covalent modification of MIF by 4-IPP and absence of MIF $+\mathbf{5}$ adducts. 

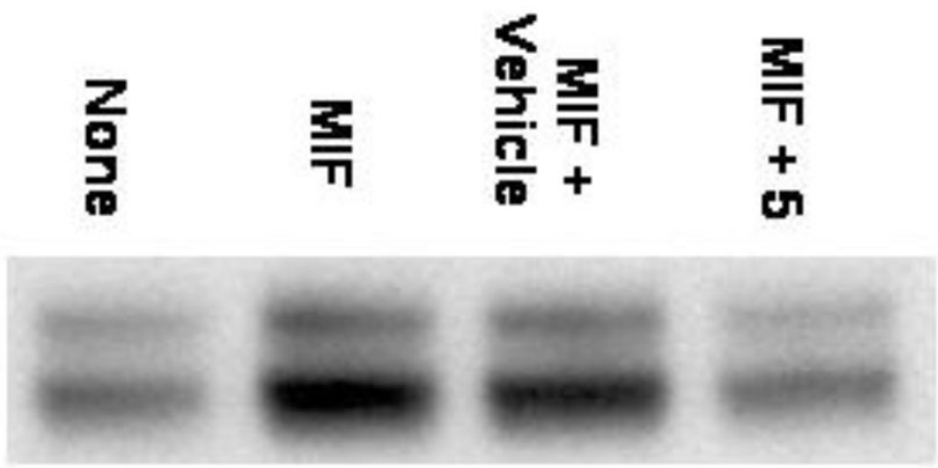

pERK1/2

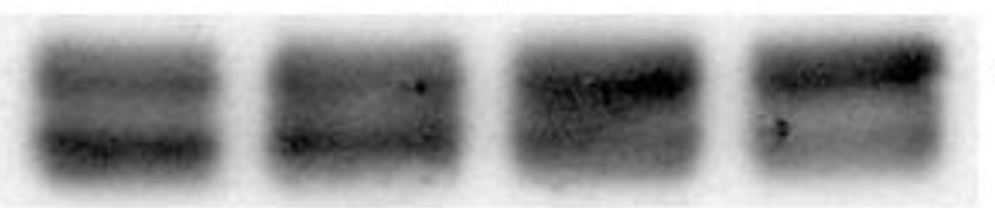

\section{Total ERK1/2}

Figure 4.

Effect of 5 on MIF-dependent ERK phosphorylation in human synovial fibroblasts. 


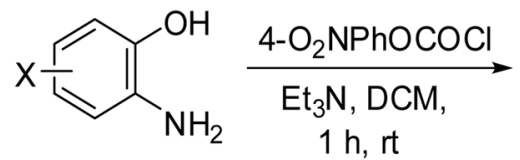<smiles>[X]c1ccc2oc(=O)[nH]c2c1</smiles><smiles></smiles><smiles>COc1cccc(Cn2c(=O)oc3ccc(C)cc32)c1</smiles>

Scheme 1.

Synthesis of $N$-benzyl-benzoxazol-2-ones. 

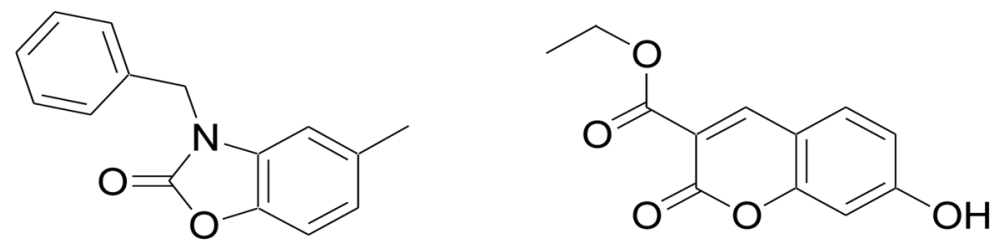

Scheme 2.

Alignment of $\mathbf{1}$ and the inhibitor in the $1 \mathrm{GCZ}$ structure. 


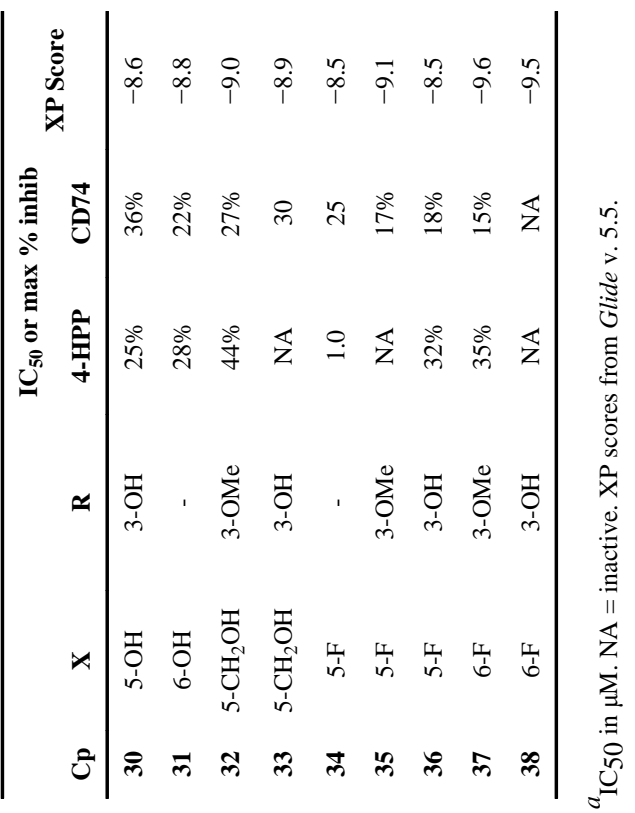

